\title{
Analisis Faktor-Faktor yang Mendorong Kinerja UKM Pada Industri Wajit
}

\author{
Riyan Faozy $^{1}$, Abdullah Ramdhani ${ }^{2}$, Rohimat Nurhasan ${ }^{3}$ \\ 1 \& 3 Fakultas Ekonomi Universitas Garut \\ ${ }^{2}$ Fakultas Ilmu Sosial dan Ilmu Politik Universitas Garut \\ Jl. Raya Samarang No. 52A Garut \\ ryan.faozy20@ gmail.com ${ }^{1}$ \\ aramdhani@fisip.uniga.ac.id ${ }^{2}$ \\ rohimat.nurhasan@uniga.ac.id $^{3}$
}

\begin{abstract}
Small and Medium Enterprises (SMEs) are business activities that support economic growth and enhance Indonesia's economy. Garut Regency is one of the areas known for culinary, handicraft, tourism and household processed products in the District of Samarang, there are traditional food processing products. The purpose of this study is to find out what factors are driving the performance of SMEs in the wajit industry in Samarang district. The method used is descriptive analysis and exploratory factor analysis. Data collection techniques used were library studies and field studies. The sampling method used in this study is a nonprobability sampling technique that is saturated samples of 45 respondents. Factors that drive the performance of SMEs 24 factors that are examined by the reduction process there are only 10 factors that can be used as new factors, after extraction and rotation, which have a correlation value of only three components that are formed correctly. Wajit industry players should be able to implement the factors that drive these performance in order to survive and thrive in improving the economy and introduce Sundanese traditional food, one of which is wajit.
\end{abstract}

\begin{abstract}
Abstrak- Usaha Kecil Menengah (UKM) adalah kegitan usaha yang menunjang pertumbuhan ekonomi dan meningkatkan perekonomiaan Indonesia. Kabupaten Garut merupakan salah satu daerah yang dikenal karena kuliner, kerajinan, parawisata dan produk olahan rumah tangga di Kecamatan Samarang terdapat produk olahanan makanan tradisonal. Adapun tujuan penelitian ini adalah untuk mengetahui fakto-faktor apa yang mendorong kinerja UKM pada industri wajit di kecamatan Samarang. Metode yang digunakan adalah analisis deskriptif dan analisis faktor eksploratori. Teknik pengumpulan data yang digunakan adalah studi kepustakaan dan studi lapangan. Penarikan sampel yang digunakan dalam penelitian ini adalah teknik nonprobability sampling yaitu sampel jenuh sebanyak 45 responden. Faktor-faktor yang mendorong kinerja UKM 24 faktor yang diteliti dengan proses reduksi maka hanya terdapat 10 faktor yang dapat dijadikan faktor baru, setelah melakukan proses extraction dan rotation, yang memiliki nilai korelasi hanya terdapat tiga component yang terbentuk dengan tepat. Para pelaku industry wajit sebaiknya dapat mengimplementasikan faktor-faktor yang mendorong kinerja tersebut agar bertahan dan berkembang dalam meningkatkan perekonomian dan memperkenalkan makan tradisional khas sunda yaitu salah satunya wajit.
\end{abstract}

Kata Kunci- Usaha Kecil Menengah, Analisis Faktor Eksploratori, Kinerja UKM.

\section{PENDAHULUAN}

Usaha Kecil Menengah (UKM) adalah kegitan usaha yang menunjang pertumbuhan ekonomi dan meningkatkan perekonomiaan Indonesia, peran UKM sangatlah penting di setiap negara, termasuk di Indonesia yang memerlukan jenis usaha baru untuk meningkatkan pendapatan negara dan menyerap tenaga kerja baru yang akan mengurangi angka pengangguran. UKM cenderung memiliki kemampuan untuk melakukan penyesuaian dengan cepat dan dapat bertahan dalam kondisi krisis ekonomi yang melanda seluruh dunia pada tahun 1998. Untuk itu, dalam meningkatkan kinerja UKM, pemerintah harus memberikan kebijakan yang memfokuskan pada pelayanan dan kemudahan bagi UKM, melakukan restrukturisasi UKM, membuka akses pelayanan perbankan khusus bagi UKM dan melakukan pembinaan sumberdaya manusia agar tingkat pengangguran dan kemiskinan menurun.

Angka kemiskinan di Indonesia pada tahun 2018 mencapai 28,01 juta jiwa. Hal ini menjadikan alas an bagi pemerintah agar mempunyai banyak program untuk mendukung perkembangan usaha mikro dengan meminimalkan permasalahan yang muncul dalam peningkatan UKM.

Kabupaten Garut merupakan salah satu daerah otonomi di provinsi Jawa Barat, yang dikenal karena kuliner, kerajinan, parawisata, dan produk olahan rumah tangga yang disukai oleh masyarakat Garut khususnya, umumnya masyarakat luar kota yang berkunjung ke kota Garut. Perkembangan UKM di kabupaten Garut mengalami pertumbuhan yang sangat pesat ini sesuai dengan program kabupaten Garut yang berperan aktif untuk mewujudkan peningkatan perekonomian Kabupaten Garut. 
Di Kecamatan Samarang terdapat produk olahan rumah tangga tepatnya di Desa Sukalaksana, Desa Sukarasa dan Desa Sukakarya terdapat makanan tradisional khas sunda yaitu wajit yang terbuat dari beras ketan yang dibungkus oleh daun jagung kering dan dijual di pusat pertokoal oleh-oleh khas Garut dan pasar tradisional. Dari sekian banyak yang memproduksi wajit, hanya sedikit dari pelaku industri wajit ini yang memasarkan produknya ke toko oleholeh karena kurangnya rasa percaya diri untuk menjalin kerja sama dan terbatasnya modal serta informasi. Oleh karena itu kebanyakan para palaku industri wajit ini menjualnya dirumah dengan harga Rp 26000/kg, harga wajit ini sering naik turun ini disebabkan harga bahan baku yang tidak stabil, jadi dalam produksinya para pelaku industri wajit menyesuaikan dengan modal yang mereka punya.

(Tabel 1 Data Produksi Industri UKM Wajit 2019)

\begin{tabular}{cccc} 
Bulan & $\begin{array}{c}\text { Bahan baku (ketan, } \\
\text { Gula, Kelapa) }\end{array}$ & Bahan Jadi & Harga \\
\hline Januari & $40 \mathrm{~kg}$ & $50 \mathrm{~kg}$ & $\mathrm{Rp22,000}$ \\
\hline Februari & $80 \mathrm{~kg}$ & $100 \mathrm{~kg}$ & $\mathrm{Rp22,000}$ \\
\hline Maret & $80 \mathrm{~kg}$ & $100 \mathrm{~kg}$ & $\mathrm{Rp24,000}$ \\
\hline April & $80 \mathrm{~kg}$ & $100 \mathrm{~kg}$ & $\mathrm{Rp} 25,000$ \\
\hline Mei & $120 \mathrm{~kg}$ & $150 \mathrm{~kg}$ & $\mathrm{Rp} 25,000$ \\
\hline Juni & $80 \mathrm{~kg}$ & $100 \mathrm{~kg}$ & $\mathrm{Rp25,000}$ \\
\hline Juli & $240 \mathrm{~kg}$ & $300 \mathrm{~kg}$ & $\mathrm{Rp27}, 000$ \\
\hline Augustus & $120 \mathrm{~kg}$ & $150 \mathrm{~kg}$ & $\mathrm{Rp26,000}$ \\
\hline September & $120 \mathrm{~kg}$ & $150 \mathrm{~kg}$ & $\mathrm{Rp} 26,000$ \\
\hline Oktober & $120 \mathrm{~kg}$ & $150 \mathrm{~kg}$ & $\mathrm{Rp} 26,000$ \\
\hline November & $80 \mathrm{~kg}$ & $100 \mathrm{~kg}$ & $\mathrm{Rp} 26,000$ \\
\hline Desember & $80 \mathrm{~kg}$ & $100 \mathrm{~kg}$ & $\mathrm{Rp} 26,000$ \\
\hline
\end{tabular}

Sumber: Pelaku usaha industri UKM Wajit Garut (2019)

Dilihat dari data produksi UKM wajit ini cenderung tidak stabil karena banyak faktor yang menjadi penghambat dalam memasarkannya, produksi wajit meningkat apabila ada pelanggan yang memesan untuk acara-acara penting seperti Idul Fitri dan acara pernikahan, hambatan yang dihadapi pelaku UKM wajit ini yaitu sering terjadinya pulang barang yang merugikan industri wajit, oleh karena untuk meningkatkan produksinya para pelaku industri wajit harus mengoptimalkan hal-hal yang mendorong kinerja UKM diantaranya: 1) Manajemen 2) produksi 3) pemasaran 4) permodalan.

Tujuan dari penelitian ini adalah untuk mengetahui faktor-faktor apakah yang mendorong kinerja UKM pada industri wajit di Kabupaten Garut.

\section{KAJIAN PUSTAKA}

Salah satu unsur yang sangat penting dalam dunia bisnis adalah manajemen. Manajemen adalah suatu kerangka kerja/proses yang membutuhkan pengarahan dan bimbingan suatu kelompok orang-orang untuk mencapai tujuan organisasi yang nyata (Terry, 2014). Dalam melakukan proses manajemen terdapat enam unsur Manajemen sebagai berikut Hasibuan (2011):

1) Men merujuk pada sumberdaya manusia baik sumber daya pimpinan maupun pelaksana.

2) Money merujuk pada aspek finansial yang diperlukan untuk mencapai tujuan yang telah ditetapkan.

3) Methods mengacu pada cara-cara yang dapat dilakukan dalam usaha mencapai tujuan.

4) Materials merujuk pada bahan-bahan yang diperlukan untuk mencapai tujuan.

5) Machines merujuk pada mesin/ alat yang diperlukan dan digunakan untuk mencapai tujuan.

Manajer dalam aktivitasnya tidak lepas dari fungsi-fungsi manajemen. Berikut adalah fungsifungsi manajemen menurut Terry dan Rue (2013) sebagai berikut:

1) Planning, diartikan sebagai proses penetapan tujuan yang akan dicapai untuk masa yang akan datang dan kegiatan apa yang harus dilakukan agar dapat mencapai tujuan itu.

2) Organizing, diartikan sebagai proses pengelompokkan orang-orang dan menentukan berbagai kegiatan penting serta memberikan kewenangan untuk melaksanakan kegiatan tersebut.

3) Staffing, menyusun sumberdaya manusia yang diperlukan, mengarahkan, menyeleksi, memberikan pelatihan dan pengembangan sumberdaya manusia.

4) Motivating, mengarahkan dan mendorong perilaku sumberdaya manusia organisasi agar kegiatannya dapat mencapai tujuan yang telah ditetapkan.

5) Controlling, mengukur pelaksanaan dengan tujuan, mengidentifikasi penyebab penyimpangan dan mengambil keputusan bersifat korektif jika diperlukan.

Menurut Kementrian Menteri Negara Koperasi dan Usaha Kecil Menengah, bahwa yang dimaksud dengan Usaha Kecil (UK), termasuk Usaha Mikro (UMI), adalah entitas usaha dengan kekayaan bersih sebanyak-banyaknya Rp 200.000.000, tidak termasuk asset tetap, dan memiliki penjualan tahunan paling banyak Rp 1.000.000.000.

Usaha mikro merupakan kegiatan ekonomi rakyat dengan skala yang kecil, bersifat tradisional dan 
informal, dalam arti belum terdaftar, belum tercatat, dan belum berbadan hukum (Zulkarnaen, 2006). Usaha mikro telah menjadi bagian penting dalam sistem perekonomian nasional melalui percepatan pemerataan pertumbuhan ekonomi dalam bentuk penyediaan lapangan usaha dan pekerjaan, penigkatan pendapatan masyarakat, ikut berperan dalam meningkatkan perolehan devisa dan memeperkokoh struktur ekonomi nasional (Musa Hubeis, 2012).

Peran UKM dalam menggerakkan perekonomian dapat berupa (1) penyediaan lapangan kerja bagi yang tidak tertampung di sektor formal, (2) Sektor UKM mempunyai kontribusi terhadap pembentukan Produk Domestik Bruto (PDB), dan (3) Sektor UKM sebagai sumber penghasil devisa negara melalui ekspor berbagai jenis produk yang dihasilkan.

Faktor-faktor yang medorong kinerja UKM terbagi dua fakor yaitu internal dan eksternal (Mc Cormick Munizu, 2010; Susilawati, Ramdani, Alamanda, \& Lesmana, 2010). Faktor internal meliputi sumberdaya manusia, finansial atau permodalan, teknis produksi, dan pemasaran. Sedangkan faktor eksternal meliputi: Kebijakan Pemerintah, Aspek Sosial, Budaya dan Ekonomi, Peran lembaga terkait seperti perguruan tinggi dan lembaga swasta lainnya.

Menurut Jauch, Giluck dan Handayani (2013) kinerja adalah merujuk ada tingkatan pencapaian atau prestasi dalam periode waktu tertentu. Kinerja sebuah perusahaan adalah cerminan dari perkembangan perusahaan itu sendiri. Kinerja merupakan serangkaian kegiatan manajemen yang memberikan gambaran sejauh mana hasil yang sudah dicapai dalam melaksanakan tugas dan tanggung jawabnya (Zuraida, Ramdhani, \& Amin, 2008).

\section{METODE PENELITIAN}

Penelitian ini menggunakan analis deskriptif dan analis faktor eksplolatori, subjek dalam penelitian ini pelaku UKM wajit yang ada di kecamatan Samarang Desa Sukarasa dan Desa Sukakarya. Data yang dikumpulkan dari hasil penyebaran kuesioner yang disebarkan kepada seluruh pelaku UKM wajit.

Sedangkan faktor-faktor yang mendorong kinreja UKM meliputi Tingkat pendidikan formal (x1), Jiwa kepemimpinan (x2), Pengalaman /lama berusaha (x3), Modal sendiri (x4), Akumulasi modal (x5), Membedakan pengeluaran pribadi (x6), Kapasitas produksi (x7) Ketersediaan bahan baku (x8), Tersedia mesin atau peralatan (x9), Teknologi modern (x10),
Melakukan kegitan promosi (x11), Saluran distribusi ( $\mathrm{x} 12$ ), Akses permodalan (x13), Kegiatan pembinaan (x14), Peraturan yang pro bisnis (x15), Penyediaan informasi (x16) Tingkat pendapatan masyarakat (x17), Tersedianya lapangan kerja (x18), Iklim usaha (x19), Pertumbuhan ekonomi (x20), Bantuan permodalan (x21), Bimbingan teknis / pelatihan pendampingan (x22), Monitoring (x23), Evaluasi (x24).

\section{HASIL DAN PEMBAHASAN}

Dalam uji KMO, apabila nilai MSA lebih besar dari 0,50 maka analisi faktor memang tepat untuk mengukur data. Sedangkan berdasarkan Uji Bartlett's Test of Sphericity, apabila nilai signifikan lebih kecil dari 0.05 maka variabel-variabel tersebut berkorelasi dan layak untuk dianalisis lebih lanjut.

Berdasarkan hasil analisis faktor melalui dapat diketahui faktor yang memiliki total eigenvalues $>1$ hanya ada 3 faktor sebagaimana ditunjukkan dalam gambar berikut.

\begin{tabular}{|c|c|c|c|c|c|c|c|c|c|}
\hline \multirow[b]{2}{*}{ Component } & \multicolumn{3}{|c|}{ Intilial Eigenvalues } & \multicolumn{3}{|c|}{ Extraction Ŝums of şquared Loadngs } & \multicolumn{3}{|c|}{ Rotation Ŝums of Şquared Loading̣s } \\
\hline & Total & \$ortVariance & Cumulative \% & Total & So of varianca & Cumulative o & Total & So ofvariance & Cumulative $\%$ \\
\hline 1 & 3.001 & 30.015 & 30.015 & 3.001 & 30.015 & 30.015 & 2.295 & 22.949 & 22.949 \\
\hline 2 & 1.982 & 19.815 & 49.830 & 1.982 & 19.815 & 49.830 & 2.127 & 21.270 & 44.219 \\
\hline 3 & 1.115 & 11.146 & 60.976 & 1.115 & 11.146 & 60.976 & 1.676 & 18.757 & 60.976 \\
\hline 4 & .864 & 8.645 & 69.621 & & & & & & \\
\hline 5 & .829 & 8295 & 77.815 & & & & & & \\
\hline 6 & .629 & 6.289 & 84.205 & & & & & & \\
\hline 7 & .577 & 5.773 & 89.977 & & & & & & \\
\hline 8 & .464 & 4.635 & 94.616 & & & & & & \\
\hline 2 & .306 & 3.062 & 97.677 & & & & & & \\
\hline 10 & .232 & 2323 & 100,000 & & & & & & \\
\hline
\end{tabular}

Sumber : Pengolah Data, 2019

Gambar 1 Total Variance Explained

Setelah diketahui 3 faktor adalah jumlah yang paling optimal, maka tabel rotated component matrix menunjukan dsitribusi dari ke 10 variabel tersebut pada 3 faktor yang terbentuk, sedangkan angka pada tabel diatas disebut factor loadings yang menunjukan besar kolerasi antara satu variabel dengan faktor 1 , faktor 2 dan faktor 3.

\begin{tabular}{l|l|l|l} 
& \multicolumn{3}{c}{ Component } \\
\hline & 1 & 2 & 3 \\
\hline x3 Pengalaman/lamaberusaha & .764 & .121 & -.147 \\
\hline x4 Modal sendiri & .417 & .540 & -.253 \\
\hline x6 Membedakan pengeluaran pribadi & .777 & .035 & -.123 \\
\hline x9 Tersedianya mesin atau peralatan & -.197 & .226 & .798 \\
\hline x10 Teknologi modern & -.027 & .496 & .470 \\
\hline x15 Peraturan yang pro bisnis & .105 & .313 & -.713 \\
\hline x20 Pertumbuhan ekonomi & .711 & .102 & -.162 \\
\hline x21 Bantuan modal & .583 & .225 & .351 \\
\hline x23 Monitoring & .154 & .805 & .218 \\
\hline x24 Evaluasi & .118 & .846 & -.111 \\
\hline Extraction Method: Principal Component Analysis. & & \\
Rotation Method: Varimax with Kaiser Normalization. & & & \\
$\quad$ a. Rotation converged in 4 iterations. & & & \\
Sumber : Pengolah Data, 2019 & & & \\
Gambar 2 Rotated Component Matrix & & & \\
\hline
\end{tabular}


Berdasrkan hasil Rotated component matrixa dapat terlihat nilai faktor loading yang paling akan menjadi faktor baru yang terbentuk, dimana faktor loading yang dulunya kecil semakin diperkecil dan faktor loading yang besar semakin diperbesar. Dengan demikian, ke 10 variabel yang direduksi hanya menjadi tiga faktor yang terdiri dari. sebagai berikut:

(Tabel 2 Hasil Analisis Faktor)

\begin{tabular}{lll}
\hline $\begin{array}{l}\text { Faktor } \begin{array}{l}\text { yang } \\
\text { terbentuk }\end{array} \\
\text { Faktor 1 }\end{array}$ & Variabel & $\begin{array}{l}\text { Faktor } \\
\text { loading }\end{array}$ \\
\cline { 2 - 3 } & $\begin{array}{l}\text { Memgalaman/lama berusaha X3 } \\
\text { X6 }\end{array}$ & 0,764 \\
\cline { 2 - 3 } & Pertumbuhan ekonomi X20 & 0,711 \\
\cline { 2 - 3 } & Bantuan Modal X21 & 0,583 \\
\hline \multirow{3}{*}{ Faktor 2 } & Modal sendiri X4 & 0,540 \\
\cline { 2 - 3 } & Teknologi Modern X10 & 0,496 \\
\cline { 2 - 3 } & Monitoring X23 & 0,805 \\
\hline \multirow{2}{*}{ Faktor 3 } & Tersedianya mesin/peralatan X9 & 0,846 \\
\cline { 2 - 3 } & Pelaturan yang probisnis X15 & 0,789 \\
\hline
\end{tabular}

Sumber: Hasil Pengolahan Data (2019)

\section{KESIMPULAN DAN SARAN}

Berdasarkan hasil penelitian yang telah penulis lakukan pada bab sebelumnya, tentang analis faktorfaktor yang mendorong kinerja UKM pada industri wajit di Kecamatan Samarang, dengan menggunakan metode deskriptif dan analisis faktor dapat disimpulkan:

1) Faktor-faktor yang mendorong kinerja UKM pada industri wajit dari 24 faktor yang diteliti dengan proses reduksi maka hanya terdapat 10 faktor yang memdorong kinerja sebagai berikut:

- Faktor 1 yaitu pengalaman berusaha/lama berusaha

- Faktor 2 yaitu modal sendiri

- Faktor 3 yaitu membedakan pengeluaran pribadi

- Faktor 4 yaitu mesin atau peralatan

- Faktor 5 yaitu teknologi modern

- Faktor 6 yaitu peraturan yang probisnis

- Faktor 7 yaitu petumbuhan ekonomi

- Faktor 8 yaitu bantuan modal

- Faktor 9 yaitu monitoring

- Faktor 10 yaitu evalusi

2) Faktor yang paling dominan dalam mendorong kinerja UKM pada industri wajit adalah tiga Faktor baru yang terbentuk sebagi berikut:
- Faktor 1 terdiri atas pengalaman/lama berusaha (x3), membedakan pengeluaran pribadi (x6), pertumbuhan ekonomi (x20) dan bantuan modal (x21)

- Faktor 2 terdiri atas tersedianya modal sendiri (x4), mesin/peralatan (x9), teknologi modern (x10), monitoring (x23) dan evaluasi (x24)

- Faktor 3 terdiri atas tersedianya mesin atau peralatan (x9) dan peraturan yang probisnis (x15)

Selanjutnya, diajukan saran sebagi berikut:

1) Untuk mendorong kinerja UKM pada industri wajit pemerintah harus memberikan dorongan kepada UKM wajit berupa kemudahan dalam akses permodalan UKM dapat menyerap tenaga kerja yang lebih banyak sehingga angka pengangguran dapat menurun.

2) Bagi pelaku UKM industry wajit supaya lebih memperhatikan pentingnya dilakukan pembukuan atau pencatatan keuangan yang berguna untuk mengontrol pengendalian modal serta perencanaan pendapatan dan efisiensi biayabiaya. Industri wajit masih terkendala dalam hal sumber daya manusia yang masih belum mengerti tentang penggunaan teknologi informasi untuk itu perlu adanya perbaikan sumber daya manusia dengan memperluas pengetahuanya tentang teknologi untuk mencapai nilai ekonomi yang tinggi bagi usaha.

3) Untuk peneliti selanjutnya yang meneliti tentang kinerja UKM untuk lebih mengembangkan pemikiran, memperbanyak referensi dan memperluas masalah yang akan dibahas agar penelitian memiliki nilai kemamfaatan yang besar bagi orang lain atau objek yang dijadikan tempat penelitian.

\section{REFERENSI}

[1] Alamanda, D. T., \& Ramdhani, A. (2011). Valuable Craft: A Co-creation as a factor of success in Zocha Vetiver Root Industry. Indonesia International Conference on Innovation, Entrepreneurship, \& Small Business. Bandung: SBM ITB.

[2] Alamanda, D. T., \& Ramdhani, A. (2018). Strategi Pemasaran. Garut: Universitas Garut.

[3] Alwi Hasan, d. (2005). Kamus besar Indonesia. Jakarta: Departeman Pendidikan Nasioal Balai Pustaka.

[4] Arikunto. (2013). Prosedur Penelitian : Suatu Pendekatan Praktik. jakarta: rineka cipta. 
[5] Astuti, M. (2013). Peningkatan usaha kecil dan menengah (UKM) berbasis teknologi content mendukung pelaksanaan masterplan percepatan dan perluasan pembangunan ekonomi Indonesia. MP3EI.

[6] Hamdani, N. A., \& Ramdhani, A. (2019). Manajemen Strategik. Bandung: Karima.

[7] Handayani, T. (2013). Pengukuran Lingkungan Makro Terhadap Kinerja Usaha. Jurnal Administrasi Bisnis, 26-37.

[8] Hardjanto, A. I. (2005). Pengantar Bisnis. Yogyakarta: Graha Ilmu.

[9] Hubeis, M. (2012). Prospek Usaha Kecil dalam Inkubator Bisnis. Bogor: Ghalia Indonesia.

[10] I Putu Lanang Eka Sudiarta, I. K. (2014). Analisis Faktor-Faktor Yang Mempengaruhi Kinerja Usaha Mikro Kecil Dan Menengah (Umkm) Di Kabupaten Bangli. e-Journal Bisma Universitas Pendidikan Ganesha Jurusan Manajemen.

[11] Mc Cormick. D., M. K. (2010). Growth And Barriers To Growth Among Nairobi's Small And Medium Size Garment Producers. World Development, vol. 25 no 7 pp 1095-1110.

[12] Moeheriono. (2010). Pengukuran Kinerja Berbasis Kompetisi. Bogor: Ghalia Indonesia.

[13] Nurhasan, R., Ramdani, R. M., Ramdhani, A., \& Akbar, G. G. (2018). Factors Affecting Entrepreneur Characteristics: A Study of Small Medium Enterprise in Garut. International Seminar \& Conference on Learning Organization (pp. 206-212). Bandung: Telkom University.

[14] Nurlatifah. (n.d.). Pengaruh persedian bahan baku dan modal terhadap jumlah produksi di UMKM kerupuk Kecamtan Tengah tani Kabupaten Cirebon.

[15] Pramudyo, A. (2013). Implementasi manajemen kepemimpinan dalam pencapaian tujuan organisasi. JBMA-Vol 1.

[16] R Terry, G. (2014). Dasar-Dasar Manajemen. Jakarta: Bumi Aksara.

[17] Ramdhani, M. A., \& Ramdhani, A. (2016). Penelitian Pemasaran. Bandung: UIN Sunan Gunung Djati.

[18] Ratrasari, A. D. (2017). Analisi faktor-faktor yang mempengaruhi keberhasilan usaha Bis. eJournal.
[19] Saladin, D. (2011). Manajemen Pemasaran, Analisis Perencanaan Pelaksanaan, Unsurunsurr Pemasaran. Bandung: CV. Linda Karya.

[20] Santosa, S. (2014). Statistik Multivariat, edisi revisi, konsep dan aplikasi dengan SPSS. Jakarta: PT. elex media Komputindo.

[21] Sawir, A. (2012). Analisis Kinerja Keuangan Dan Perencanaan Keuangan Perusahaan. Jakarta: Gramedia Pustaka Utama.

[22] Sugiyono. (2012). Metode Penelitian Kuantitatif, Kualitatif dan $R \& D$. Bandung: Alfabeta.

[23] Sugiyono. (2013). Statistik Untuk Penelitian. Bandung: alfabeta.

[24] Sugiyono. (2014). Metode Penelitian Bisnis. Bandung: Alfabeta.

[25] Sulistyo, C. d. ( 2011). Small and medieum Industries in Asian Developing Countries. Asian Development Review vol-1, 29-45.

[26] Susilawati, W., Ramdani, A., Alamanda, D. T., \& Lesmana, M. O. (2010). Analysis of the Factors that Influence Consumer Purchase Decisions in the Snack Product (Case study in BANCI as an Alternative Healthy Food. The Indonesia International Conference on Innovation, Entrepreneurship, and Small Business (pp. 589-593). Bandung: SBM ITB.

[27] Sutrisno. (2003). Manajemen Keuangan (Teori, Konsep dan Aplikasi), Edisi Pertama, Cetakan kedua. Yogyakarta: Ekonisia.

[28] Suwanto, T. Y. (2011). Manajemen Sumber Daya Manusia. Bandung: Alfabeta.

[29] Tambunan, T. (2012). UMKM di Indonesia. Bogor: Ghalia Indonesia.

[30] Tarigan, R. (2007). Pengaruh tingkat pendidikan terhadap tingkat pendapatan perbandingan antar empat peneltian. Scholar articel.

[31] Tjiptono, F. (2008). Strategi Pemasaran Edisi III. Yogyakarta: Andi Offset.

[32] Zuraida, R., Ramdhani, A., \& Amin, A. S. (2008). Analysis of the Cultural Factors Impact on the Development of Entrepreneurship in Garut. Jurnal Ilmiah Psikologi, 1(2), 183-196. doi:http://dx.doi.org/10.35760/psi.2008.v1i2.30 0 